Revista Iberoamericana, Vol. LXXIII, Núm. 220, Julio-Septiembre 2007, 595-613

\title{
HETEROSEXUALIDAD Y DIFERENCIAS GENERACIONALES EN LA LITERATURA ECUATORIANA
}

\author{
POR \\ FERNANDO ITURBURU \\ State University of New York-Plattsburgh
}

\begin{abstract}
Homosexualities in Latin America literature, are not comfortable notions to contend with, and lesbianism in particular seems to give critics a hard time. Silvia Molloy, "Reading Teresa de la Parra"

Gay history from the time homosexuality was invented as a category could be written in terms of this disappearing and reappearing act -almost as if homosexuality were nothing but a reaction, the responses of a social group to its own invention.
\end{abstract}

Leo Bersani, Homos

INTRODUCCIÓN

El presente ensayo es una breve historia de la literatura homoerótica en Ecuador y busca promover una visión multicultural y ampliar la lista de obras representativas de la identidad nacional. Para ello se toman cuatro momentos: inicios del siglos xx, literatura de los años 30, el período de transición de los 50 y, finalmente, los últimos quince años. En este ultimo período, y al que le dedicaremos consecuentemente la mayor parte del presente ensayo, encontramos más y mejores voces que expresan los dilemas de la sexualidad disidente.

Lo que Ecuador le ofrece al mundo pasa por el filtro de la crítica y la intervención de mecanismos que imponen el gusto, el sentido literario y los programas de escritura de comercial. El resultado no es un número justo ni completo de autores. Hay otro grupo, más desconocido aún: quienes, a pesar de representar de manera espléndida el tiempo histórico en que vivieron, de no ser rescatados por la investigación contra hegemónica, permanecerán para siempre en la sombra. ${ }^{1}$ Entre ellos encontraríamos a autoras coloniales como

\footnotetext{
1 “According to Said, criticism should be a constant reexperiencing of beginning, promoting not authority but noncercive and communal activity" (Beginnings 379-80). La posición de Said es particularmente pertinente a este trabajo porque apoya y articula un pensamiento que promueve el diálogo en vez del centralismo ideológico. Véase también su The World, the Text, and the Critic. El detalle de la discusión sobre quiénes merecen o no figurar en una lista de autores "clásicos"
} 
Gertrudis de San Ildefonso, Madre Catalina de Jesús Herrera y Madre Antonia Lucía Maldonado. ${ }^{2}$ Forman parte de este grupo también Jorge Rivadeneyra, Abdón Ubidia, Francisco Proaño Arandi, Agustín Vulgarín, Fernando Nieto Cadena, Carlos Eduardo Jaramillo, Sonia Manzano, Fernando Cazón, Carlos Béjar y el gran poeta negro Antonio Preciado, por citar a unos pocos. A estos, debemos añadir el subgrupo de escritores, principales en este ensayo, que ha sido totalmente ignorado por la crítica, en gran parte debido a que escriben desde el centro de una sexualidad disidente que desafía la ideología dominante y los mitos nacionales mientras cuestiona las relaciones humanas y sus principios éticos. Ellos son: Luis Miguel Campos, Juan Carlos Cucalón, Clara Ayala, Carolina Portaluppi, Maritza Cino y Roy Sigüenza.

Estudios de literatura gay y lesbiana han tenido un gran impulso en otros países de América Latina y España (Foster, Smith, Bergmann), y han privilegiado análisis a escritores como Federico García Lorca, Luis Cernuda, Salvador Novo, Manuel, Puig, Pedro Lemebel, Reynaldo Arenas, Peri Rossi y Virgilio Piñera, e incluso se ha dado cabida a quienes han generado producciones catalogadas de "homoeróticas" sin que necesariamente haya una correspondencia entre sus biografías y sus discursos literarios. ${ }^{3}$ En Ecuador, en cambio, se ha silenciado a quienes sí escriben desde el interior del mundo homosexual, y se han omitido textos que cuestionan el llamado falo-logo-centrismo y heterosexualidad. Para comprender esta política de marginación, en el contexto de la historia literaria ecuatoriana, sería apropiado tomar en cuenta tres momentos: a) las manifestaciones en el período colonial y de independencia, ${ }^{4}$ b) la percepción del personaje homosexual en la primera mitad del siglo xx, y, c) las variaciones a dicha percepción en los últimos cincuenta años. En el primero podemos incluir algunos pasajes de la literatura de conquista y colonial, sobre todo descripciones de indios, negros y mujeres. En el segundo, debemos establecer la manera en la cual la llamada “Generación del 30”5 percibió y contribuyó a la

(nacionales o no), en realidad debe partir de una autocrítica del gusto de quienes la promueven, así como reconocer que, como lo hace Henry Louis Gates al hablar de la literatura afro-estadounidense, "If a nationality comes into its own through the production of literature, the apparatus of recognition -the 'selection of classics' to which E.R. Curtius refers- remains integral to its realization. Inevitably, the process of constructing a group identity, at the margins as at the very center, involves active exclusion and repudiation; self-identity requires the homogeneity of the self-identical. Ironically, then, the cultural mechanism of minority self-deconstructions must replicate the mechanism responsible for the rendering it marginal in the first place. To recur again to Weimann: 'the process of making certain things one's own becomes inseparable from making other things (and persons) alien’ (321), en Greenblatt y Gunn, eds.

${ }^{2}$ Véanse Autobiografía..., Lecturas prohibidas..., "Marianita...” y “Gertrudis...”.

${ }^{3}$ Frecuentes son los estudios desde dicha perspectiva de textos de Jorge Luis Borges, Fernando Pessoa, José Donoso y Lezama Lima, por ejemplo.

${ }^{4}$ Particularmente pertinente, para este período, son el trabajo de Michel Foucault: Histoire de la sexualité, y el conjunto de la obra de Asunción Lavrin, correspondiente a la situación femenina, por dar ejemplos y herramientas de reconstrucción histórica y documental de la conducta sexual e institucional, sobre todo de la Iglesia Católica, en época anteriores.

${ }^{5}$ Véase obras como Juyungo de Adalberto Ortiz, Huasipungo de Jorge Ycaza, Las cruces sobre el agua de Joaquín Gallegos Lara, la antología de narraciones de montubios (campesinos de la costa ecuatoriana) llamada Los que se van, escrito por el Grupo de Guayaquill, La Tigra, de José de la Cuadra. 
expansión de una ideología claramente patriarcal, misógina y homofóbica, en medio de sus proclamas de igualdad social avaladas por la militancia socialista y marxista de sus integrantes. ${ }^{6}$ El tercer momento incluye a dos tipos de autores: los que reproducen, desde el exterior de la cultura homoerótica (Artieda) y los que escriben desde el interior de la cultura homosexual, lésbica o bisexual. Para nuestro estudio es necesario tomar en cuenta cuatro obras que prefiguran una voz literaria sexualmente disidente: la novela $A$ la Costa de Luis A. Martínez, el cuento “Un hombre muerto a puntapiés” del sorprendente Pablo Palacio, y los poemas de David Ledesma e Ileana Espinel.

\section{PRINCIPIOS DEL SIGLO XX}

A la Costa, de Luis A. Martínez (1868-1909), es una novela escrita a principios del siglo xx. En ella se cuentan los dilemas propios de familias oligárquicas y la pugna de conservadores y liberales a fines del siglo xıx, época de cambio del modelo latifundista serrano por el liberalismo comercial costeño. Para entenderla mejor se hace oportuna la definición de "homosociality" dada por Terence Brunk:

Homosociality refers to the broad range of socially structured interactions between people of the same sex. Such interactions include but are not limited to gay and lesbian sexuality. The concept...has been primarly to investigate same-sex interactions that are not overtly sexual. These investigations are crucial to feminism because they unveil structures of power, knowledge, and oppression not immediately available to interrogations of relationships between the sexes. (198)

En A la Costa, los protagonistas de esta obra, Salvador y Luciano, son una pareja masculina cuyos lazos de amistad sugieren la existencia de un deseo de mutua compañía enmarcado en referencias regionalistas de Costa/Sierra. La siguiente cita, a pesar de su extension, es necesaria porque reúne de manera compacta los detalles que ilustran un deseo homosexual en el contexto socio económico de los protagonistas:

En la universidad conoció Salvador a un joven provinciano, descenciente de esa hermosa clase media, que no pica muy alto en asuntos de nobleza y que sin embargo, por el talento, las aptitudes y el patriotismo, es la primera de la República. Una simpatía irresistible y antes nunca sentida llevó al joven quiteño a entablar amistad con Luciano Pérez, amistad única y primera en su vida. Pérez, asimismo, simpatizó con Ramírez, y desde entonces los dos formaron una asociación inseparable, aun cuando en lo físico y lo moral eran dos entidades absolutamente contrapuestas. El uno era la fuerza y la energía, el otro la debilidad y el temor; el provinciano parecía por su estatura y esbeltez un boxeador yankee, y el quiteño rubio, pálido y débil, una señorita enfermiza; Luciano era un huracán, Ramírez un céfiro; el gigante estaba destinado a vencer en todas las luchas de la vida, el chico a perecer en el primer combate. Pérez era la voluntad incontrastable,

\footnotetext{
${ }^{6}$ Véase también Baldomera de Alfredo Pareja Diezcanseco, Atahualpa de Benjamín Carrión o Argonautas de la selva de Leopoldo Benítez Vinueza, El chulla Romero y Flores, de Jorge Ycaza o Nuestro Pan de Enrique Gil Gilbert.
} 
Ramírez una inteligencia luminosa, pero sin movimiento, y en el mundo el triunfo las más veces es de la primera.

En seres contrapuestos ¿Por qué nació inconsciente una amistad íntima? Fenómeno bastante común, pues las mejores amistades nacen de caracteres opuestos. Luciano vió en Salvador un ser débil, inofensivo, bueno; admiró en ese cuerpo raquítico un alma limpia de la roña del disimulo y de la envidia, que se debatía solitaria, presa de mil desconocidos deseos y ansiosa de otra más fuerte en quien confiarse, y Luciano amó a Salvador con el cariño del hermano mayor al menor, con el del fuerte y seguro de sus fuerzas al débil; amor sin envidia, sin interés, amor siempre noble y sin embustes. Salvador vió en Luciano, al hombre gigante dominador de la materia y de la voluntad, futuro conquistador de gloria acaso, y le admiró, le temió luego, y después amóle con entusiasmo. He aquí el secreto de la amistad de Luciano y Salvador. (48)

Aquí se resumen los elementos básicos de la relación entre ambos personajes, marcada por el origen social, referencias estéticas y rasgos sexuales: la universidad es el espacio del pensamiento ilustrado y del encuentro masculino: En A la Costa vemos que el mutuo reconocimiento del deseo homosexual minimiza las diferencias de clase social en pro del realce de lo sensual de los personajes ("Hermosa," "provinciana”). Así, la "simpatía irresistible y nunca antes sentida” de Salvador por Luciano se traduce en “amistad".

En la literatura, la amistad muchas veces ha sido la envestidura del amor por el mismo sexo porque es el único medio para protegerse de la tensión que provoca la homofobia. No obstante su importancia en la historia literaria, la crítica ecuatoriana no ha analizado los lazos masculinos porque

critics with an anti-homosexual agenda have made a point of separating love between men from sex between men. They call the former "friendship" (or at most, "platonic love") and only the latter "homosexuality". Their aim is to appropiate all texts about male love for the institution of heterosexuality, and, at the same time, to diminish the literature of homosexuality by allowing it only to be about sex. (Woods 184)

En la novela de Martínez encontramos el tópico del alma errante, divida, que busca volver a su lugar de origen, en una apelación a la imagen del hermafrodita que da paso a usa serie de dualidades: "El uno era la fuerza y la energía, el otro la debilidad y el temor; el provinciano parecía por su estatura y esbeltez un boxeador yankee, y el quiteño un rubio, pálido y débil, una señorita enfermiza". ${ }^{7}$ Esta división se muestra en términos de "boxeador yankee” y "señorita enfermiza”. El "quiteño (“céfiro”) es contrapuesto al costeño y su vitalismo campesino (“huracán”). El segundo párrafo responde a la pregunta “¿Por que nació inconsciente una amistad íntima? Y la responde así: “Fenómeno bastante común” (itálicas mías). Martínez apela a un episteme psicoanalítico propio de su época: el deseo es "inconsciente” y lo entrega al lector en forma de protección del débil por el fuerte: "un alma limpia de la roña del disimulo y de la envidia, que se debatía solitaria, presa de mil desconocidos deseos, y ansiosa de otra más fuerte en quien confiarse"

${ }^{7}$ Baste citar los casos del Dr. Jekyll and Mr. Hyde de Robert Louis Stevenson, o Frankenstein de Mary Sheller. 
(itálicas mías). Salvador es un sujeto femenino y etéreo (“un alma”) atrapado en una encrucijada personal, y Luciano un sujeto masculino que se feminiza y quiere encontrarse con su parte ausente y pura, con su propia subjetividad negada, puesto que él es esa "otra [alma] más fuerte en quien confiarse”.

\section{LitERATURA DE LOS AÑOS 30}

Muchos años después de que Martínez presentara esta pareja masculina en la literatura ecuatoriana, Pablo Palacio (1906-1947), ${ }^{8}$ el gran ignorado de los años 30, sacó a la luz un cuento sorprendente llamado "Un hombre muerto a puntapiés". Este, que poco a poco ha merecido la atención de algunos críticos y ecuatorianistas, ${ }^{9}$ introduce como protagonistas del cuento, en oposición al delicado trato de amistad de A la Costa, al homosexual pederasta, a un niño acosado sexualmente, y a su padre, que hace las veces de ajusticiador. El cuento muestra también la respuesta no menos enfermiza y violenta de la sociedad, contada a través de una mezcla de estilo periodístico y especulaciones metodológicas sobre investigación policial. Al final, el homosexual es asesinado mediante una golpiza:

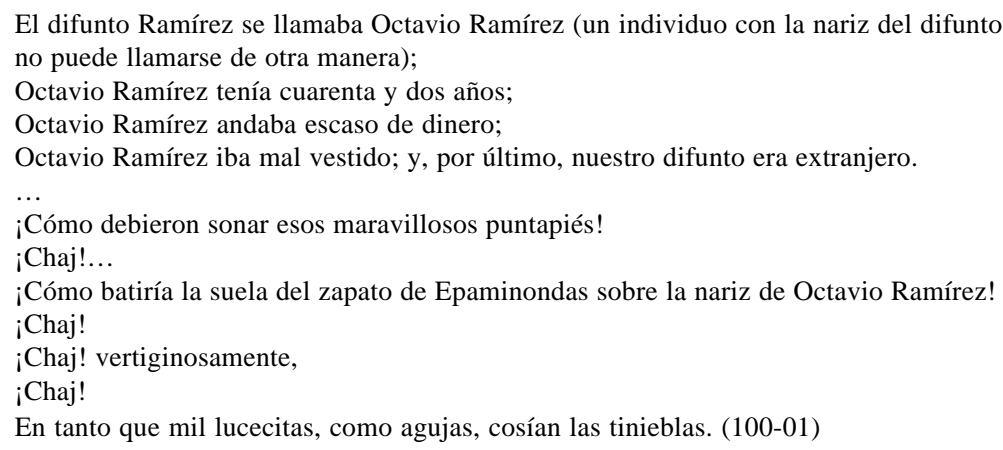

La violencia de este episodio de pederastia indica la opción por lo marginal y el poder descriptivo de Palacio, pues este supo captar desde el realismo un momento de la vida urbana en la cual el personaje homosexual, fuera del closet, entra en la escena social para ser retratado como enfermo y ser vapuleado, amenazado y asesinado. En la literatura ecuatoriana, el realismo social, tan en boga en los años en que escribió Palacio, dejó también otros ejemplos de homofobia, misantropía y misoginia, sobre todo en las obras del llamado “Grupo de Guayaquil”. En los últimos años, esta opción artística por describir

\footnotetext{
${ }^{8}$ La breve pero excelente obra de Pablo Palacio incluye Un hombre muerto a puntapiés (1927), Débora (1927) Novela: Un nuevo caso de mariage en trois (1925), dada a conocer como parte de la novela Ojeras de virgen cuyos originales se extraviaron; Vida del ahorcado (1932). Teatro: Comedia inmortal (1926).

${ }^{9}$ Véase Corral. A más de las decenas de artículos que se encuentran en revistas y diversos sitios del internet, para una crítica autorizada véase la edición preparada por Miguel Donoso Pareja.
} 
la violencia cotidiana, el realismo y el rol que juegan los aparatos represivos y la criminalidad, ha sido recogida en la película Ratas, rateros y ratones de Sebastián Cordero. De gran acogida nacional, la película describe las relaciones familiares y los entramados de la "amistad" masculina -como ya vimos en los protagonistas de A la Costay promueve estereotipos regionalistas. En efecto, en ella el personaje bueno, joven e inocente, será nuevamente otro Salvador, un joven quiteño, primo del peligroso delincuente guayaquileño de humilde estrato Angel (versión actualizada de Luciano). Lo que caracteriza a Angel es su resentimiento social, sarcasmo y búsqueda del dinero fácil a través del atraco. Pero la peligrosa vida que lleva Angel es imitada por Salvador, y se explica en las propias palabras del joven quiteño: “él me acolita, yo le acolito”. No obstante la dificultad de narrar de manera totalizadora estas contradicciones, la película reactualiza la violencia urbana ya contada por los escritores del 30. ${ }^{10}$

EL PERÍODO DE TRANSICIÓN DE LOS AÑOS 50

Luego de Martínez y Palacio, hacia mediados de los años 50, apareció en Guayaquil un grupo de escritores bajo los membretes de “Generación Huracanada” y “Grupo 7”. Entre sus miembros se encontraban dos poetas, fallecidos ya, que el tiempo ha tratado de reivindicar: David Ledesma Vásquez (1934-1961) e Ileana Espinel Cedeño (19332001). ${ }^{11}$ Ellos vivieron en un sistema social que, a más de estar marcado por las tensiones sociales del subdesarrollo, promueve la discriminación y la censura moralista. Sus obras reflejan oblicuamente los dilemas y las crisis que aquejan a la comunidad homosexual. Los casos de Ledesma y Espinel son pertinentes a este inventario porque hacen uso de símbolos, tropos, figuras, tópicos y formas verbales que fraguan una identidad sexualmente disidente.

En su "Balada de un transeúnte” Ledesma dice:

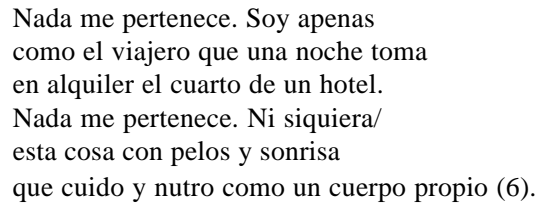

Y en “Extraño” escribe:

\footnotetext{
${ }^{10}$ Para un estudio más detallado de esta obra y su circunstancia, veáse mi Lecturas prohibidas.... ${ }^{11}$ La bibliografía de Ledesma incluye: Cristal (Guayaquil, 1953); Club 7 -coautor- (Guayaquil, 1954); Gris (Caracas, 1958); Los días sucios -coautor- (Guayaquil, 1960); Cuaderno de Orfeo (Guayaquil, 1962); Antología personal -póstumo-(Guayaquil, 1962); y dejó varias obras inéditas: La risa del ahorcado o La corbata amarilla; Poemas para Guatemala; Elegías; Teoría de la llama; Cuba en el corazón. Entre los libros de Ileana Espinel tenemos Piezas líricas (1957), La estatua luminosa (Caracas 1959), Triángulo (1960), Arpa salobre (1966), Diríase que canto (1969), Tan solo trece (1972), Poemas escogidos (1978), La corriente alterna (1978), Solo la isla (1995).
} 
Un hombre a quien jamás he conocido visita una ciudad que ya no existe -largo sabor de muerte le atraviesa de parte a parte la sonrisa amargaentra en una casa donde nunca ha estado y se sienta a esperar que nadie llegue. Sobre su corazón suenan mis pasos. (6)

En estos poemas, la subjetividad del personaje homoerótico aparece en un contexto personal donde los espacios (ciudad, casa, cuerpo) son arrancados de su construcción histórica y biológica para darle paso a una voz que acepta un destino negativo irremediable.

Al igual que David Ledesma, Ileana Espinel, su solidaria amiga y colega, ofreció al público versos que son un arte combinatoria de su circunstancia personal, a veces salpicada de información social y política, comprensible por su oficio de editorialista de un diario local. En sus poemas, ella enarbola la palabra para construir un sujeto femenino a través de la negación personal dialéctica, como lo apreciamos en “Apenas algo”:

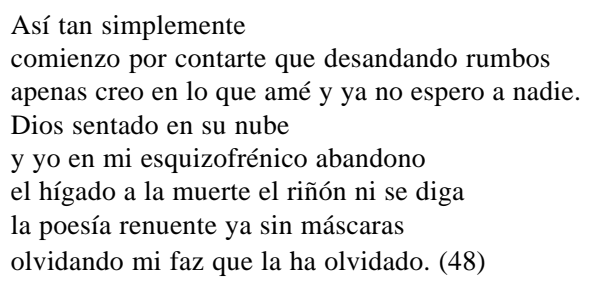

Aquí el cuerpo, en su aspecto más fisiológico, también ocupa un lugar central, pues Espinel enfatiza en su demoronamiento orgánico y en la crisis psicológica. Algo similar ocurre en "Balance mortal":

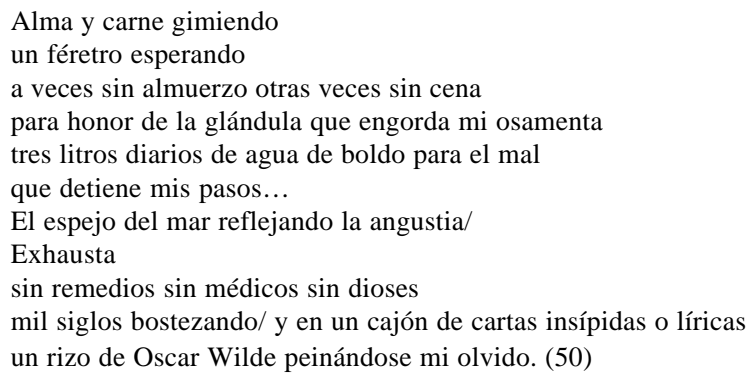

Aquí, el registro poético se vale de la herencia modernista, por el uso de palabras de universos semánticos diferentes, pero insistiendo en una tanática poética del desgaste físico que es "como la luz el pus y las carcomas” (51). 
Tanto en Ileana Espinel Cedeño como en David Ledesma Vásquez encontramos lo personal mezclado con conflictivos dilemas artísticos y literarios: la desazón de vivir, la falta de entusiasmo y la ironía. Ambos fueron víctimas de una circunstacia ambigua: la de pertenecer a un medio cultural que privilegia la censura en vez de la promoción literaria mientras rehúsa aceptar el aporte literario de una expresión poética irreverente.

Martínez, Palacio, Ledesma y Espinel permiten entender mejor el estado actual de la voz disidente en Ecuador, y de la cultura letrada que está más allá de la penumbra de los bulliciosos bares y cantinas del trópico, una voz que tampoco se queda en las frías callejuelas de los Andes o en los shows travesties de la madrugada, sino que busca pormenorizar la condición del amor y del deseo por el mismo sujeto sexual, y fomentar un afán de reivindicación y solidaridad en el marco social en el que fueron producidas.

LOS ÚLTIMOS QUINCE AÑOS DE PRODUCCIÓN

El primero de los actuales escritores de la disidencia sexual es el quiteño Luis Miguel Campos (1960). ${ }^{12}$ Historiador, activo dramaturgo, prolífico narrador, hijo de la gran escritora ecuatoriana Alicia Yánez Cossío, Campos tiene el aval de una gran cultura y tradición letrada dentro de su familia. Reconocido en su ciudad como el mejor representante del teatro costumbrista, con obras de éxito y actualidad, la novela que nos ocupa ha merecido muy poca atención. En La zorrilla del cañaveral aparece nuevamente lo que subyace a "la amistad masculina" de A la Costa: el deseo por el mismo sexo, aunque retomado de manera mucho más elaborada, en medio de discusiones que pormenorizan el proceso de construcción tanto del concepto de homosexual como de su recepción.

La zorrilla del cañaveral es una novela iniciática, que navega entre el didactismo narrativo del siglo xIx y el experimentalismo de la segunda mitad del siglo xx, pues hace gala de complicaciones formales y narratológicas: hay un diario (escrito por Abel, uno de los protagonistas) que es recuperado por el narrador de la novela, el mismo que advierte al lector sobre los cambios de voces que se registrarán páginas más adelante); hay también párrafos en primera persona de Simón, otro personaje, en los que cuenta su vida y los violentos avataes de la construcción de una identidad sexual en un pensionado. La obra también abunda en confesiones entre compañeros de clase, violaciones, intimidaciones, juegos sexuales cruzados, parodia estilística, uso del chisme (o rumor) como medio de desprestigio, exploración del mundo educativo segregado, problemáticas causadas por cambios de edades o ciclos (de la infancia a la adolescencia), estigmas contra los homosexuales de parte de los padres: "Es algo así como una enfermedad, ¿sabes? -dijo mamá- una enfermedad muy peligrosa...homosexualidad” (85). O enfrentamiento y dilucidación de los temores y del qué dirán:

\footnotetext{
${ }^{12}$ Campos en realidad nació en Cuba, pero creció en Quito, y su obra se debe a ese lugar, e incluye los siguientes títulos: Compañero del reforestador. Quito: Intercooperación, 1996. La zorrilla del Cañaveral. Quito: Casa de la Cultura, 1987. La marujita se ha muerto con leucemia: juguete local. Quito: Ana Capicúa, 1993. Leche de luna. Quito: Sinab, 1997. Precipitación de la alborada: a raíz del estupor que produce un cuarto oscuro. Quito: Casa de la Cultura, 1982. Obra infantil no apta para niños. Quito: Offset, 1984. Juana de Jesús. Quito, 1984.
} 


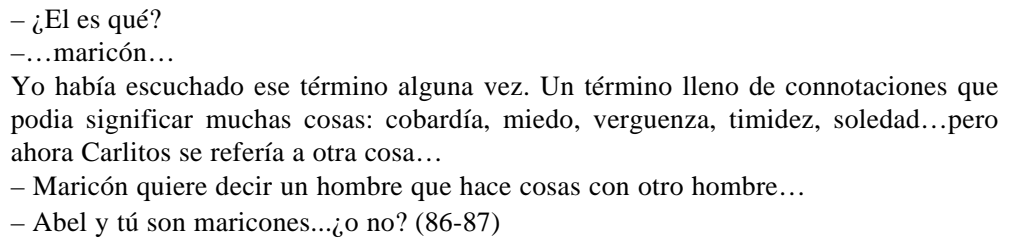

A diferencia de A la Costa, y de otras obras que merecen la atención de la crítica si se quiere ahondar en este rastreo de las parejas masculinas en la literatura ecuatoriana, ${ }^{13}$ la novela de Campos expone y dilucida de manera frontal los estereotipos de la homofobia y el falo-logo centrismo. En este sentido, es un paso adelante en la asunción de una problemática, discurso y estilo propiamente homosexuales, situándo la problemática en un abanico interpretativo más amplio, así como en un contexto más definido. Ya no se trata sólo de una cultura homosocial. Gracias a Campos y, consecuente a los siguientes escritores de este ensayo, desde ahora se puede verificar con mayor precisión un estilo y estructura en el discurso homosexual, el mismo que tiene como núcleos semánticos la otredad, pues "the homosexual suffers a categorical, perhaps even ontological, otherness since he is made to feel his 'unlikeness' to the heterosexual acts and persons who gave him birth” (Bergman 30). Otredad que se suma a la homosexualidad como una condición permanente, en oposición a las "etapas" homoeróticas, en las cuales incurren muchos heterosexuales. El estilo homosexual reclama también la característica de ser una condición intercambiable: el deseo es siempre por el mismo sexo, no la substitución de un heterosexual inalcanzable. Y finalmente, de ser una relación de equidad, no como las que históricamente se registraron en la antigua Grecia o partes de Africa, en las cuales los roles activo/pasivo están relacionados con una cultura de poder y generacional (31).

Después de Campos debemos detenernos en el guayaquileño Juan Carlos Cucalón (1963). Autor de varios cuentos y de dos novelas inéditas, su obra se encuentra publicada en las antologías Entre el cero a la nada (1994) y Mensaje en una botella (2003). Cucalón vivió aproximadamente diez años en Guatemala, Estados Unidos y Japón, donde realizó estudios literarios. La saludable asimilación de esta experiencia le permitió adoptar una actitud directa, irreverente y franca en su estilo literario. Formalmente, dio sus primeros pasos en los talleres literarios de la Universidad Católica de Guayaquil y del Banco Central, aunque se puede decir que llegó ya maduro a esos espacios, como lector y escritor. Las narraciones de la primera antología, escritas en spanglish, se preocupan más de contar situaciones ocurridas en Estados Unidos y llegan a veces a un diletantismo que genera excesos narrativos y exageraciones antimoralistas. Su mérito literario radica en la inclusión de una voz personal nueva en la literatura ecuatoriana, la mezcla de dos idiomas diferentes y el protagonismo de personajes homosexuales. La segunda etapa de Cucalón empieza hacia 1996 y concluye pocos años más tarde. En ésta, el escritor se descentra de su experiencia estadounidense, baja al ombligo del mundo y se mete, a ratos mecánicamente,

\footnotetext{
${ }^{13}$ En este sentido, apropiada sería una relectura de Las cruces sobre el agua -novela fundadora de la "guayaquileñidad" que narra las vicisitudes de los obreros y la clase media en el año 1922-, de Joaquín Gallegos Lara.
} 
en los recovecos de la mentalidad nacional ("Monjas 2 Terminal”, "El chapa cachudo”, "El viaje maravilloso”, "Lúcidos”) en un estilo que a veces nos recuerda el de Reynaldo Arenas o Fernando Vallejo. ${ }^{14}$ Dice Cucalón en “El clavo”:

La miré en serio y guardé el pañuelo, ella copió el gesto como si fuera mi reflejo en un espejo. Nos miramos fijo y en nuestros rostros afloraron muecas que al verse correspondidas se hicieron estruendosas carcajadas. No podíamos dejar de reir. Nos agarrábamos el estómago y la cabeza, sentía que se me aflojarían los esfínteres. Sospeché próximo un paro respiratorio e intenté contenerme, hasta que ella, sacudiéndose como yo, me extendió un trapo empapado de brillante rojo y entornando sus ojos se desplomó. (69)

Vemos cómo el personaje masculino usa uno femenino para exponer su dualidad y un proceso personal inconcluso, como lo hicieron Martínez, Ledesma y Espinel. De lo publicado por Cucalón, los textos que llaman la atención por el tratamiento del argumento, la importancia del espacio y la descripción de protagonistas, son "El único trapito de Van Dick” y "Un leve indicio”. En el primero, el narrador describe el interior de una iglesia, los personajes miran erotizados a un Cristo crucificado, y se utiliza una trama detectivesca para explicar el origen del cuadro, incluyendo referencias de envidia y plagio entre Van Dick y Zurbarán. El cuento puede ser leído como una crítica a la Iglesia Católica dentro de la narrativa humorística o grotesca, o como crónica periodística, de mucha recepción en Ecuador. ${ }^{15}$ Asimismo, puede verse como una fuerte crítica al catolicismo y sus afanes reguladores de la sexualidad (Foucault, Histoire...). En "Un leve indicio", en cambio, Cucalón describe un lugar marginal, en el cual viven hombres enfermos que van muriendo de uno en uno, en medio del silencio y la expectativa. Leprosería, sidario, cárcel, internado, seminario o asilo de ancianos, en "Un leve indicio” Cucalón hace gala de polisemia, sugerencia simbólica y narración indirecta para contar los estragos que provocan el aislamiento de los "otros", la incomunicación y el dolor de partir de este mundo. En este cuento, Cucalón desenmascara el sistema de censura impuesto por la sociedad y la manera en que sus mecanismos de represión son interiorizados o resistidos:

Estoy salvado, al menos por esta noche. Lo he percibido clarísimo, en toda su acritud, estoy seguro de que, aunque vegetariano, eso último fue un eructo. Pero, ¿de quién fue? ¿de Andrés o de Simón?... ¿Qué mensaje traerá la inmovilidad de esta comuna?, ¿qué será?, que, ¿̇mañana yo tampoco abriré la ventana como los otros? No. Yo puedo decir con certeza que seré el último en cerrar su ventana. (82-83)

Junto a la obra de Cucalón se ubica la de Clara Ayala (1957). Esta cuentista comparte características generacionales y de grupo con Cucalón, y sus textos se encuentran en

\footnotetext{
${ }^{14}$ Sobre todo novelas como El mundo alucinante y El color del verano, El desbarrancadero y La virgen de los sicarios.

${ }^{15}$ Como ocurre en otros países de América Latina, en Ecuador también se nota un apreciable número de cultivadores de estos estilos, conocidos desde tiempos republicanos, con el notorio despliegue comunicativo que provocaron los diarios en el siglo xix, entre ellos podemos nombrar a Medardo Angel Silva, Modesto Chávez Franco, y entre los contemporáneos Rodolfo Pérez Pimentel y Jorge Martillo Monserrate.
} 
antologías similares. Ex-estudiante de la Universidad Católica y ahora profesora de literatura, Ayala ha venido trabajando en los últimos años en los talleres dirigidos por el escritor Miguel Donoso Pareja. ${ }^{16}$ Ella estructura sus cuentos con detalladas descripciones y un narrador en tercera persona, prefiere temas como la soledad y las contradicciones de mujeres de la clase alta y nos introduce su mundo personal a través de un discurso irónico y compasivo:

Había ido a Nueva York a buscar emociones fuertes e inolvidables. Pero todos buscamos emociones. Intentaba convencerme a mí mismo de lo acertado que había sido programarle un viaje así...Ella está fuera de contexto para quien quiera leer algo actual. Qué podría aportar de valioso para la narrativa una personalidad así de gris, cuando lo que realmente nos interesa es escribir sobre temas candentes donde la imaginación pueda dar rienda suelta a todas sus posibilidades. (Libro de Posta 19-20)

Ayala hace gala de la influencia de escritoras como Marguerite Duras o Virginia Wolf, cuyas obras son intertextualizas en sus cuentos ("No es Alicia”), o de meta-discursos que irrumpen en la narración: "Lili aun escuchaba disparos rezagados en el inconsciente cuando despertó...Lili se levantó a las 9...Sus canales telepato-femeninos no funcionaban” (Mensaje..., 39).

Al describir los dilemas de la condición femenina de la clase alta, Ayala los redefine enmarcándolos en conflictos dominados por la tristeza, la soledad o el suicidio, recurso ya advertido como parte del programa de escritura feminista (Woods 217). Dichos conflictos pueden llevar a la muerte, como ocurre con el suicidio de la protagonista de "Un feriado largo", en el cual la abulia del fin de semana y la desorganización del tiempo diario se topan con la angustia y el vacío que se siente en una vida desprovista de deseos y contacto con el mundo exterior: "Yo nunca entendí por qué lo hizo -parecía que quiso llegar hasta las últimas consecuencias-pero eso es una interpretación atrevida” (Mensaje... 45). En Ayala, así como en Cucalón, encontramos lo que Rowe elabora y propone como una urgente necesidad de encontrar en el discurso del "otro" un apoyo en la lucha contra los discursos centralistas, puesto que es en la dimension de la otredad donde se puede desafiar la represión que sufren tanto mujeres, pobres, niños y negros y, por extension, homosexuales y lesbianas (Rowe 199).

Los cuentos de Ayala tienen también elementos fantásticos, teatrales, abstractos y de ciencia ficción, como en "La mujer en el balcón del aluminio” y “Tomás”. En el primero se incluyen poemas precedidos de instrucciones, como si fueran monólogos, y se describe a una mujer situada en diferentes ángulos del mismo espacio. Este cuento, verdadero ejercicio de desubicación del personaje femenino, tiene la virtud de unir lo lúdico con la reflexión formal sobre su género sexual:

\footnotetext{
${ }^{16}$ Uno de los escritores más conocidos de Ecuador, Donoso Pareja, ha publicado cuento, novela, poesía y ensayo. En los años sesentas fue exiliado a México por la dictadura military y allí desarrolló una incesante labor cultural, editorial y literaria, marcada por su dirección del programa nacional de Talleres Literarios, de los cuales surgió un gran número de destacados escritores mexicanos, hoy vigentes. A su regreso a Ecuador, a incios de los ochentas, continuó con sus actividades culturales y literarias, y de sus talleres también salieron destacadas figuras de las letras ecuatorianas.
} 


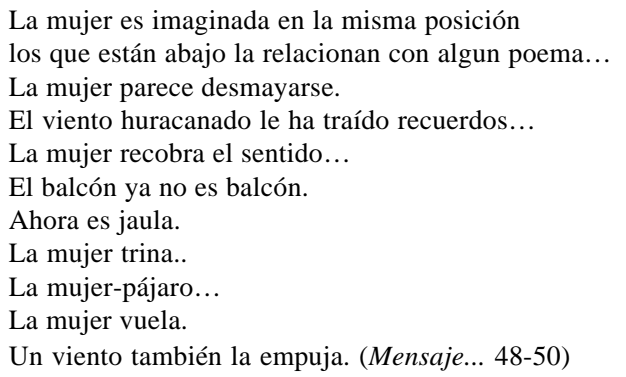

En “Fantasmas", Ayala nos brinda una conmovedora proclama homoerótica y bisexual, y con tono firme y directo, dice:

Los fantasmas no me perdonan. Yo no los perdono. Mañana quiero ir a comprar zapatos,
quiero que sean botines con corte masculino. Tienen el estilo que me gusta. Pueden ser
negros. Ya los tengo vistos. No pienso desviarme a la librería. Ni pienso sentirme culpable
si no compro el último libro editado por Tusquets...Prefiero hacer el amor. Los fantasmas
me van a convencer de que no ama igual cualquier hijo de vecino que Henry Miller, que
la diferencia está en la angustia de la palabra: follar, tirar, coger. La palabra agarra,
aprieta, frota, igual que los genitales en plena acción. ¿Tendrán razón? Traigo a la
memoria a la Wolf. Me hace sentir más libre. Amo como mujer, amo como hombre. (51)

Cucalón y Ayala describen en prosa con un punto de vista auténtico, solidario y realista. En sus cuentos no hay ni banalización ni exageración, ni falsa modestia ni plataforma de convencimiento. Algo similar encontramos en los versos de Maritza Cino y Carolina Portaluppi, aunque de manera más incisiva y sintética.

Maritza Cino ha publicado varios libros de poesía y, al igual que sus compañeras de generación, divide su tiempo entre la escritura, la coordinación de talleres de lectura y escritura, y la enseñanza secundaria y universitaria. ${ }^{17}$ Carolina Portaluppi, quien tiene una larga experiencia asesorando organizaciones populares de mujeres, es también muy activa de su labor literaria. Ambas centran su poesía en reflexionar sobre la condición femenina, y en ambas es notoria la influencia de Delmira Agostini, Gabriela Mistral, Alfonsina Storni, Cristina Peri Rossi y el eco de Virginia Wolf y Simone de Beauvoir. Ellas se emparentan también con una sensibilidad posmoderna, pues convergen en sus poéticas varios temas y preocupaciones de esta escuela, como la "obsessive fixation on nothingness, absence, triviality, exhaustion, entropy, and blankness...to turn the oppressive conditions of urban life into possibilities of literary creation and an ultimate transvaluation of those circumstances” (Rowe 181-82).

${ }^{17}$ A cinco minutos de la bruma. Guayaquil: Viñeta, 1987. Algo parecido al juego. Guayaquil: Viñeta, 1983. Entre el juego y la bruma. Antologia: 1983-1993. Guayaquil: Casa de la Cultura, 1995. Infiel a la sombra: Quito: Libresa, 2000. Ha aparecido también en varias antologías, como Seis poetas ecuatorianas vivas. Cuaderno de Poesía 20. Barcelona: Alandar, 2004. 
En Maritza Cino la reflexión personal es incesante. Para ella, el arte y la poesía la ayudan a sortear conflictos existenciales:

\author{
El arte me salvó \\ prestidigitador de instintos \\ redimió mi espanto \\ con su humor concupiscente. (91)
}

Su deseo se manifiesta abiertamente sensual y sexual a la vez:

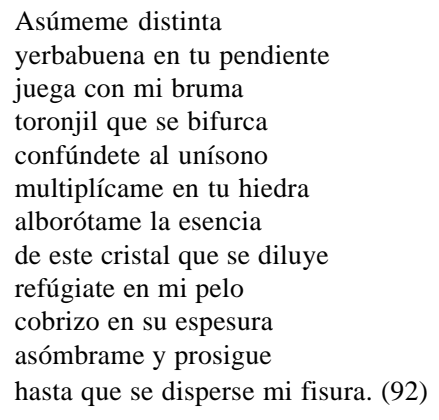

Arte y deseo forjan una identidad y una voz culta y consciente de sus vaivenes. En Cino, la escritura se transforma en ejercicio liberador para plasmar y exponer sus testimonios personales, y mostrar el mecanismo que estructura y da equilibrio a su vida:

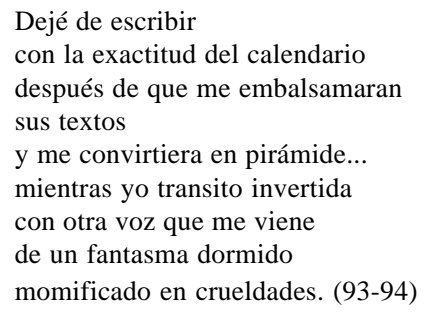

Algo similar encontramos en la poesía de Carolina Portaluppi cuando dice:
La Muerte
Ay, la muerte.
$\mathrm{Al}$ fin un lugar
donde escaper
del silencio. (72)

Dentro del tono apocalíptico, la muerte genera salvación; el silencio de la rutina, en cambio, es lo negativo: 


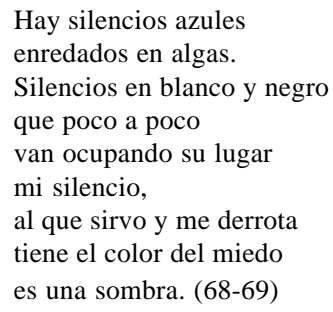

La muerte es fiesta y, posiblemente, también un signo de madurez avalado por un proyecto literario de afirmación de su subjetividad femenina:

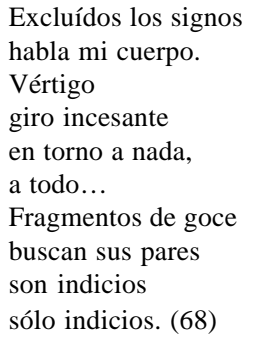

Así, la poesía de Portaluppi se abre a coordenadas surrealistas e impresionistas, acaso modernistas, pero desde un punto de vista de su género sexual.

Tanto en Cino como en Portaluppi, el tema femenino va de la mano con la preocupación por ser fiel al oficio de la poeta-mujer que, en su caso, es de unir calidad literaria y ética del mensaje. Sus voces buscan también lo cotidiano, dice Portaluppi:

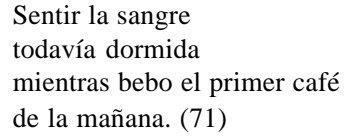

Y más adelante:

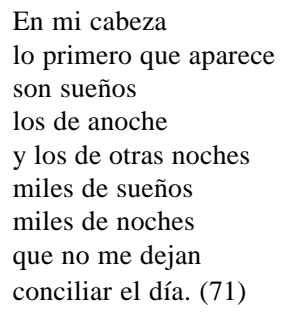


De la misma manera en que apareció la muerte que acababa con el silencio, en otros poemas aparece el deseo de la mujer por la mujer. En este deseo, cuyo cuerpo es universalizado en la geografia mundial y las preocupaciones ecológicas, sin dejar de lado el humor y un sutil tono de nostalgia, dice Portaluppi:

\author{
Estos ojos son los mismos \\ que ayer midieron la tierra. \\ Sobrevivientes al deshielo \\ fueron descubriendo \\ que los cambios climáticos \\ de tu cuerpo, \\ el ensanchamiento de mi línea \\ ecuatorial \\ y el vaivén de nuestras mareas \\ no son ajenos. \\ Son culpa del calentamiento global. (69-70)
}

Y luego:

\author{
Cuando la mira con esos ojos fríos \\ como caracoles \\ le da la espalda \\ y empieza esa larga caminata \\ hacia los polos, \\ ella recuerda que ninguna especie \\ pudo sobrevivir al hielo. \\ A la mañana siguiente \\ la gente la mira con repugnancia \\ y ella no sabe por qué/ es tan felíz. (70-71)
}

Para terminar, revisemos el trabajo del poeta Roy Sigüenza (1958), el mismo que, así como Cucalón, entrega en primera persona su universo poético homosexual unido a referencias y citas concretas de Kavafis, Auden, Cernuda, Lorca, entre otros. ${ }^{18}$ La obra de Sigüenza es breve y se encuentra distribuída en pocos libros. ${ }^{19}$ Sus poemas son cortos, sobrios, mordaces, a ratos abstractos, y cuestionan desde el humor la conducta sexual

${ }^{18}$ En la tradición hispanoamericana, su obra encuentra sorprendentes parecidos con la de Ernesto Bañuelos Enríquez (California, 1948), sobre todo por el verso corto y el predominio del desenfadado tono autobiográfico.

${ }^{19}$ La hierba del cielo. Quito: Casa de la Cultura, 2002. Ocúpate de la noche. Cuenca: Universidad de Cuenca, 2000. Tabla de mareas. Cuenca: Universidad de Cuenca, 1998. En la misma editorial apareció luego el poemario “A la sombra del corsario” de Franklin Ordóñez Luna (Loja, 1973); que se mueve en las mismas coordenadas poéticas y sexuales que la obra de Sigüenza Sin embargo, por la dificultad que encierra tratar el tema de la homosexualidad en Ecuador, en gran parte por el temor a ser marginados por el medio, resulta infructuoso determinar si se trata de escritores que se definen como tales, o se trata sólo de la utilización de voces poéticas homoeróticas hechas por poetas heterosexuales, cosa común en el medio. Algo similar se podría decir de la obra de Cristóbal Zapata. 
represiva de la sociedad ecuatoriana. Con un toque aristocrático y decandente, producto de sus ávidas lecturas y quizá del síndrome Kavafis, quien “choses to write as homosexual, with homosexual desires, within a homosexual tradition. This meant he had to circulate his poems privately. It was a limitation he accepted, if unwillingly, rather than compromise the poetry itself. Sex was so much a part of his self-identity that it could not be left out" (Woods 187). Fuera de algunas intromisiones de “autor implícico”, la obra de Sigüenza, a pesar de su indiscutible calidad, ha pasado desapercibida, condenada también a la penumbra o al comentario de grupos reducidos, muchas veces escritores acólitos, o a ser despojada de su sentido sexual. En sus poemas sobresale el tono autobiográfico, como en “Gracias por la rosa del mundo”, donde escribe:

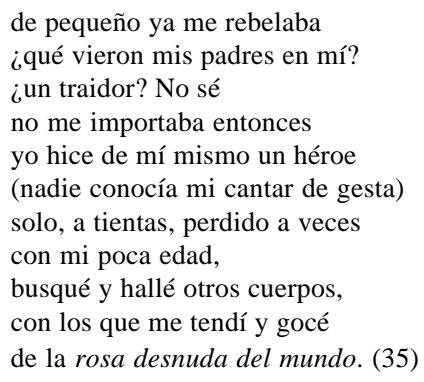

En este poema, la familia es el universo negado que impone como alternativa la soledad y el asialmiento infantil, y una adolescencia sexualmente activa. Su léxico es claro y sencillo, aunque el contenido complejo, pues la verdad que Sigüenza describe es presentada como natural (“de pequeño ya me rebelaba”), opuesta a la cultura familiar y nos remite a las dicotomías filiación/afiliación y natural/cultural (Said 614), que reflejan puntos de vista diametralmente opuestos y que generan gran parte de los conflictos personales y sociales.

La poesía de Roy Sigüenza abraza la vida diaria y marginal de los homosexuales, de la cual es testigo y participante; su voz está imbuída de historia y de militancia a favor de los marginados, tal como ocurre en "Vista de la ciudad venérea":

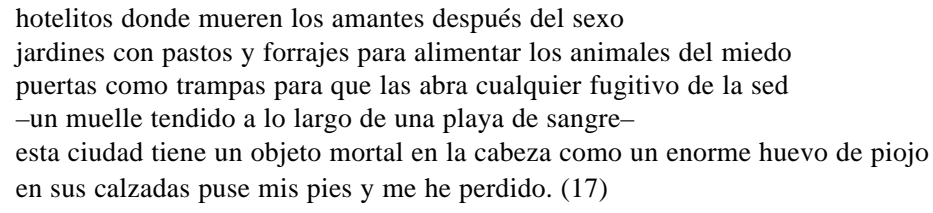

Si en los “hotelitos" ronda la muerte es porque el espacio urbano deviene en poética marginal de ambientes exteriores trastocados: el jardín es del miedo, las puertas son trampas, la playa es de sangre y la ciudad tiene un objeto nauseabundo: un "huevo de piojo”. En esa distopía, la voz poética del disidente moral está perdida, y sólo queda un 
testimonio solitario. Sigüenza, al igual que Cucalón, denuncia sin merodeos los elementos más atormentadores de la vida homosexual en una sociedad fundada en el discrimen.

En este inventario inicial del estilo homoerótico en la literatura ecuatoriana rastreamos el inicio de esta corriente y su fundación en la novela A la Costa y el cuento "Un hombre muerto a puntapiés”. En la novela vimos a una pareja masculina cuya relación ocurre en términos de una llamada “amistad” pero que, a la vez, está cargada de sentidos trágicos y mecanismos de autorrepresión sexual, lo cual construye una subjetividad marginal y limitada, subyacente a lo largo del texto. En el cuento, en cambio, encontramos ya al personaje homosexual representado como pederasta, contra quien se ejerce una violencia física y legal que representa la brutalidad con la que la sociedad reacciona. Revisamos luego dos casos que quedaron en la penumbra de la anécdota personal y el mensaje subliminal: Ileana Espinel Cedeño y David Ledesma Vásquez. Al final, comentamos la obra de los narradores Luis Miguel Campos, Juan Carlos Cucalón y Clara Ayala, y de las poetas Martiza Cino, Carolina Portaluppi y Roy Sigüenza, en quienes la “cultura letrada” a la que apelan es de clase media-alta con un discurso más europeizado que latinoamericanista o ecuatorianista.

El presente ensayo es sólo una muestra de la producción literaria de una cultura históricamente relegada pero que, poco a poco, emerge a la luz de una recepción más amplia y de metodologías pertinentes (Sedgwick 1-63, Brunk, Berman, Bergmann), y de la urgente necesidad por enriquecer un proceso multicultural. Comparado con el apoyo y publicidad que han tenido escritores no-heterosexuales de otros países, el caso de estos ecuatorianos tiene mucho que ver con la represión sexual que su sociedad ejerce en la vida diaria y en los círculos artísticos, y también con una falta de apertura editorial incluyente cuyo alcance sea, por lo menos, nacional. Se trata, entonces, de un claro ejemplo de lo que Berlant y Warner llaman heteronormatividad, es decir "the institutions, structures of understanding, and practical orientations that make heterosexuality seem not only coherent -that is, organized as a sexuality- but also priviled” (355). Por ahora, bástenos con esta muestra para verificar lo que Ecuador ofrece. Campos, Cucalón, Ayala, Cino, Portaluppi y Sigüenza muestran el ámbito personal y subjetivo de la sexualidad disidente, e incluyen en sus obras información social y política, estética y literaria, para describir una condición humana que cuestiona los límites de la heterosexualidad. El tono de sus obras es intimista pero también de proclama, y el deseo es expresado de manera visceral o tenue. Ellos asumen, desarrollan y testimonian el paso de un estilo homoerótico a uno homosexual, bisexual o lésbico. Los dilemas que exponen en sus obras están sujetos, como en cualquier otra producción histórica, a férreos sistemas de poder, represión, o conocimiento. Corresponde una vez más a la crítica contra hegemónica establecer los detalles de dichos dilemas en la construcción de nuestra identidad, así como su lugar en el concierto latinoamericano. En cualquier circunstancia, se trata del aporte de quienes viven en el aún desconocido ombligo del mundo. 
Anderson-Imbert, Enrique. Literatura hispanoamericana: antología e introducción histórica. Vol I y II. New York: Holt, Rinehart and Winston, 1960.

Artieda, Pedro. La homosexualidad masculina en la narrativa ecuatoriana. Quito: Eskeletra, 2003.

Ayala, Clara. Libro de posta. Antología: nuevos cuentistas de Guayaquil. Miguel Donoso Pareja, ed. Guayaquil: Imaginaria, 2000.

Mensaje en una botella. Miguel Donoso Pareja, ed. Guayaquil: Banco Central, 2003.

Bergman, David. Gaiety Transfigured. Gay Self-Representation in American Literature. Madison: University of Wisconsin Press, 1991.

Bergmann, Emilie y Paul Julian Smith, eds. ¿Entiendes? Queer Readings, Hispanic Writings. Durham: Duke University Press, 1999.

Berlant, Lauren y Michael Warner. "Sex in Public”. The Cultural Studies Reader. Simon During, ed. London: Routledge, 1993. 354-67.

Bersani, Leo. Homos. Cambridge: Harvard University Press, 1995.

Brunk, Terence. "Homosociality”. Encyclopedia of Feminist Theory. Elizabeth KowoleskiWallace, ed. New York: Garland, 1997. 198-99.

Campos, Luis Miguel. La zorrilla del cañaveral. Quito: Casa de la Cultura Ecuatoriana, 1987.

Cino Maritza. Indignados tus hijos del yugo. Miguel Donoso Pareja, ed. Guayaquil: Imaginaria, 2003. 89-94.

Cordero, Sebastián. Ratas, ratones, rateros. Vanguard Cinema, 2001.

Corral, Wilfrido H., ed. Obras Completas, Pablo Palacio (1906-1947). Nanterre: ALLCA XX, Université Paris X, 2000.

Cucalón, Juan Carlos. Entre el cero y la nada. Guayaquil: Universidad Católica, 1994. Mensaje en una botella. Guayaquil: Banco Central, 2003.

Donoso Pareja, Miguel. Recopilación de textos sobre Pablo Palacio. Habana: Casa de las Américas, 1987.

Espinel Cedeño, Ileana. Antología Poética. Guayaquil, 2001.

Foster, David William. Gay and Lesbian Themes in Latin America Writing. Austin: University of Texas Press, 1991.

Foucault, Michel. Histoire de la sexualité. Paris: Gallimard, 1976. Surveiller et Punir. Paris: Gallimard, 1975.

Franco, Jean. An Introduction to Spanish American Literature. London: Cambridge University Press, 1969.

Iturburu, Fernando. Lecturas prohibidas de la literatura ecuatoriana. Guayaquil: Universidad Católica, 2002. Redrawing the Boundaries. The Transformation of English and American Literary Studies. Stephen Greenblatt y Gilles Gunn, eds. New York: MLA, 1992.

Autobiografía y misticismo femeninos en la Colonia. La Relación escrita por Madre Josefa de la Providencia sobre Madre Antonia Lucía Maldonado. New Orleans: UP of the South, 2000. 
“Marianita de Jesus, Saint”. Encyclopedia of Women in World History. Asunción Lavrin, ed. Oxford (en imprenta).

“Gertrudis de San Ildefonso, La Perla Mística”. Introducción y edición crítica. Asunción Lavrin, ed. Puebla: Conferencia Latinoamericana de la Iglesia, México, (en imprenta).

Ledesma Cedeño, David. Poemas de David Ledesma. Guayaquil: Casa de la Cultura, 1985.

Martínez, Luis A. A la Costa. Quito: Antares, 1994.

Molloy, Silvia. "Reading Teresa de la Parra”.¿Entiendes? Queer Readings, Hispanic Writings. Emilie Bergmann y Paul Julian Smith, eds. Durham: Duke University Press, 1999. 230-56.

Palacio, Pablo. Obras completas. Quito: Antares, 2003.

Portaluppi, Carolina. Indignados tus hijos del yugo. Miguel Donoso Pareja, ed. Guayaquil: Imaginaria, 2003. 67-72.

Rowe, John Carlos. "Postmodern Studies”. Redrawing The Boundaries. The Transformation of English and American Literary Studies. Stephen Greenblatt y Giles Gunn, eds. New York: MLA, 1992. 179-208.

Said, Edward. “Secular Criticism”. Critical Theory Since 1965. Hazard Adams y Leroy Searle, eds. Tallahassee: University Press of Florida, 1986. 604-22.

Sedwignky, Eve Kosofsky. Epistemology of the Closet. Berkeley: University of California Press, 1990.

Sigüenza, Roy. La hierba del cielo. Quito: Casa de la Cultura, 2002.

Smith, Paul Julian. Representing the Other. Race, Text, and Gender in Spanish and Spanish American Narrative. Oxford: Clarendon Press, 1992.

Woods, Gregory. A History of Gay Literature: The Male Tradition. Hong Kong: Yale University Press, 1998. 